\title{
与那国島におけるコウノトリCiconia boyciana の集団越冬
}

\author{
江崎保男 1 宮良全修2*
}

\section{Wintering of Oriental White Storks in Yonaguni Island, the Westernmost Japan}

\author{
Yasuo Ezaki ${ }^{1}$ and Zenshu Miyara ${ }^{2 *}$
}

\begin{abstract}
A flock of Oriental White Storks appeared in Yonaguni Island, the westernmost Japan in November 1993. The flock size at the time was eleven. The communal roost that was formed in a lowland valley with paddy field seems to have been shifted to another paddy field area during a short period in March 1994, probably due to human disturbance at the former place. Another important habitat for storks was pasture where they foraged. The flock of eleven storks were never recorded after December, but it is highly probable that the eleven birds overwintered in the island, since roosting of a single bird apart from the communal roost with ten birds was suggested for a night in February. Large flocks at the communal roost were recorded last on $19 \mathrm{March}$ and thereafter one or two storks were witnessed until the summer of the year.
\end{abstract}

Key words: Communal roost, Paddy field, Pasture, Human disturbance, ciconia boyciana.

日本のコウノトリCiconia boyciana は19 世紀には都市部でもふつうに生息していたと考えら れるが (Blakiston \& Pryer 1878, 丹羽 1892, 清棲 1952), 1960 年代に野外繁殖個体群が絶滅し た（但馬文化協会 1984，池田 1994）。見在は少数が全国各地で冬期に稀に観察されるが（日本 鳥学会 1974，樋口 1976，小笠原・泉 1977，藤巻 1988），1993 年 11 月にはこれまでにない大 きな群が八重山諸島の与那国島に出現した。本稿では 1993 年 11 月から 1994 年 3 月にかけて 著者らがみずから調查収集した記録と現地で得られた信頼できる情報にもとづいて，与那国島 でのコウノトリの越冬状況について報告する。

与郲国島は日本最西端 $\left(24^{\circ} \mathrm{N}, 123^{\circ} \mathrm{E}\right)$ に位置する面積 $29 \mathrm{~km}^{2}$ の島で, 台湾との国境に面し ている。島の中央を東西に標高 $200 \mathrm{~m}$ 前後の山地が走り, その周囲には比較的平坦な台地と低 地が入り交じって存在し，崖となって海に落ち込んでいる。山地の斜面はビロウ Livistona chi-

Received 22 May 1995, Revised 21 August 1995, Accepted 25 August 1995.

1 T669-13 兵庫県三田市弥生が丘 6 丁目 姫路工業大学自然・環境科学研究所／人と自然の博物館

${ }^{2}$ T907-18 沖縄県八重山郡与那国町祖納 与那国町教育委員会

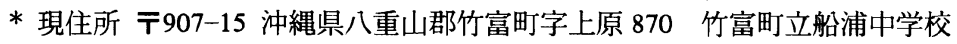

${ }^{1}$ Institute of Natural and Environmental Sciences, Himeji Institute of Technology (and Museum of Nature and Human Activities, Hyogo), Yayoi-ga-oka 6, Sanda 669-13 Japan

2 Yonaguni Town Board of Education, Sonai, Yonaguni-cho, Yaeyama, Okinawa 907-18 Japan

* Present address: Funaura Junior High School, Uehara 870, Taketomi-cho, Yaeyama 907-15 Japan 
Table 1. Number of Oriental White Storks recorded in the two roost sites, Tarumai and Ubungita, in early morning (before 800) or late evening (after 1800) after the location of the latter site on 7 March 1993. Columns filled with symbols (-) indicate that the site was not searched for storks.

\begin{tabular}{rlcc}
\hline Date & Time & \multicolumn{2}{c}{ Number of storks in } \\
\cline { 3 - 4 } & & Tarumai & Ubungita \\
\hline 8 March & morning & 0 & 9 \\
9 March & evening & 0 & 8 \\
10 March & evening & 0 & 2 \\
11 March & morning & 0 & 9 \\
12 March & morning & 0 & 9 \\
13 March & evening & 0 & 0 \\
14 March & morning & - & 9 \\
15 March & morning & - & 10 \\
16 March & morning & 10 & 0 \\
17 March & morning & 10 & - \\
18 March & morning & - & 0 \\
19 March & morning & 10 & 0 \\
\hline
\end{tabular}

nensis やイタジイ Castanopsis sieboldii などの林となっているが，台地や低地はサトウキビ畑や 水田に開墾されており，海岸の台地の上は牧場となっていることが多い。

この島の南西部の山あいに位置するマンタバル（満田原）の水田地帯（約 20 ha）でコウノト リの群が地元住民によって発見されたのは11月23 日であった。翌24日から26日にかけての 午前中 $(9: 00)$ あしくは夕方 $(17: 30 \sim 18: 00)$ に 4 回この水田を訪れたところ, 毎回 11 羽のコ ウノトリが水をはった水田内に群で確認され, かっ 11 月 26 日の昼過ぎ $(13: 00)$ にはマンタバ ルから約 $700 \mathrm{~m}$ 北西に位置するクブラ（久部良）の集落の上空を 11 羽のコウノトリが群で飛 んでいるのを, 久部良中学校の職員と生徒が目撃している。したがって当初与那国島に飛来し たコウノトリは 11 羽のまとまった群をつくっていたと考えられる (Appendix 1 参照)。

11 月 27 日の午後 $(14: 30)$ にはマンタバルにコウノトリの姿はなく, ほよ゙なく丘陵を隔てて $500 \mathrm{~m}$ 南に位置するタルマイ (樽舞) 峡谷の海岸の崖の上に 11 羽が群でいるのを発見した。夕 ルマイは海岸の崖（標高 $50 \sim 60 \mathrm{~m}$ ） と内陸の丘陵（標高 $60 \mathrm{~m}$ ）にはさまれた細長い谷 $(2.5 \mathrm{~km}$ $\times 0.3-0.5 \mathrm{~km})$ で, 谷の内部は水をはった水田と湿原, 丘の斜面の一部は牧草地となっている。 この日以降 1994 年 3 月 19 日までの間に著者らがこの谷を訪れた 45 日のうちの 37 日 (82\%) にこの谷でコウノトリをみることができた。一方, 11 月 27 日以降, マンタバルでは上空を通過 する以外はコウノトリの姿をみることができなかった (Appendix 1 参照)。

著者らが別に行なった調查の結果，1994年 2 月 25 日から 3 月 1 日の間の 4 夜はタルマイの 水をはった水田で日によって 9 羽あるいは 10 羽のコウノトリが集団でねぐらをとっていたこ とがわかっている (Ezaki \& Miyara in press)。3 月 1 日の日没後 $(19: 10)$ と 3 月 2 日の日の出直 後 $(7: 00)$ にタルマイの水田で 10 羽のコウノトリが確認されたので, 3 月 1 日から 2 日にかけ ての夜もタルマイに集団ねぐらが形成されていたとみてよい。3 月 2 日の日没後 (18:50) あ同 様に 10 羽が水田に群をつくっていたが，19 時に車が谷の中に進入したので，一斉に谷から飛 び去ってしまった。翌早朝 $(7: 15)$ には夕ルマイにはコウノトリの姿はなく, 正午過ぎ $(12$ : 


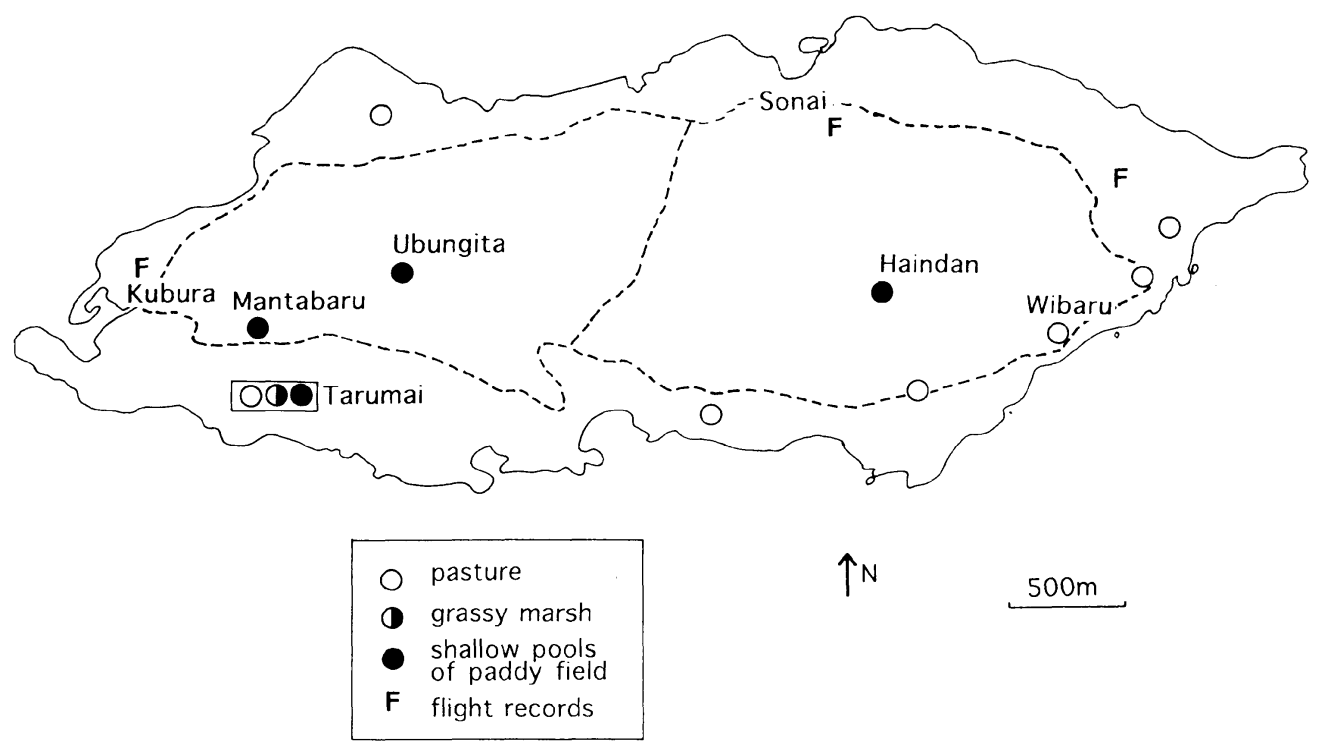

Fig. 1. Fourteen localities and their habitats where Oriental White Storks were recorded between November 1993 and March 1994. District names are added to some important localities. A circular road system (dotted line) links the two major towns, Sonai and Kubura, to coastal area all over the island.

15)には 7 羽が確認されたものの, 夕方 $(19: 00)$ には再び姿を消していた。 3 月 4 日の早朝 (6: 50)にもタルマイにコウノトリの姿はなかったので，このねぐらは放棄されたと判断し，北東 に $1 \mathrm{~km}$ 離れた普段人が近づくことのない久部良岳山腹に位置するウブンギタの水をはった水 田（約 2 ha）を 7 時 25 分に訪れたところ 9 羽の群を発見した。 3 月 6 日の日没直前 $(18: 30)$ に はタルマイで 9 羽の群が記録されたがすぐに飛び立った。これを探して 19 時にウブンギタに 到着すると 9 羽の群がいたので, 先にタルマイを飛び去った群がウブンギタに移動した可能性 が高いと考えられた。翌早朝 $(7: 30)$ にもウブンギタで 9 羽の群が確認されたので， 3 月 6 日か ら 7 日にかけての夜は，ここで集団ねぐらが形成されたとみてよい (Appendix 1 参照)。3 月 8 日以降の早朝と夕方の記録に着目すると，日によって群がみられなかったり，群の大きさが変 動したりしたものの，3 月 15 日の早朝までは，ウブンギタで群がみられ，タルマイにはコウノ トリの姿がなく，16日の早朝以降はこの逆のパターンがみられたので (Table 1), タルマイに ねぐらをとっていた群が一時的にウブンギタへねぐらを移した後, 再びタルマイへねぐらを戻 したとおおむねみることができる。タルマイへもどった群も，3月19日の早朝に爆竹の音に驚 いて飛び去り，これ以降 10 羽近くの大きな群の記録はとだえた（Appendix 1 参照）。

調査期間内の島内のコウノトリの目撃記録は全部で 91 件あったが, このうち 66 件はマン夕 バル, タルマイ, ウブンギタの 3 カ所でえられたあのである。それ以外の 25 件のうち 11 月 26 日のクブラ上空の 1 件以外はすべて単独個体もしくは 2 羽の記録であった。これら単独もしく は 2 羽のコウノトリが繰り返し記録されたのは島の南東部の海岸近くのウィバル（帆安上原） の牧草地であった (Appendix 1 参照)。ここでは 12 月 23 日の昼過ぎに飛翔中のコウノトリが 
目撃されたので, この翌日以降調査期間終了時まで, 調査基地となったソナイ（祖納）の集落 からマンタバル, タルマイあるいはウブンギタを訪れる前後に, ウィバルを通る島の東半分の 周遊道路を自動車で回りコウノトリをさがす調查を頻繁におこなった。また，この調査の 5 回 に 1 回程度の割合で島の西半分の周遊道路沿いの調查ああわせておこなった。これらの調查の なかで合計 13 地点でコウノトリが目撃された (Fig. 1)。上空飛翔の記録のみが得られた 3 地点 をのぞく 10 地点はすべて水をはった水田もしくは牧草地（あるいは夕ルマイのようにこれら 双方を含む地域）であったことがわかる。ウィバルほかの牧草地ではコウノトリが採慨してい るのを頻繁に目撃しており, 牧草地が越冬中のコウノトリの重要な餌場になっていたことがう かがえる。

さて, 渡来直後にみられた 11 羽の群は 12 月 3 日のタルマイでの記録が最後であり, これ以 降は夕ルマイもしくはウブンギタで最大 10 羽の群が記録されたにとどまった。しかし，2月末 から 3 月にかけてタルマイのねぐらで就時するコウノトリの数が, 日によって 9 羽もしくは 10 羽と変動したことがわかっているので (Ezaki \& Miyara in press), この時期タルマイとは別に 少数個体が就侍する場所があったことは確実である。実際 2 月 28 日の夕方に, ウィバルの西方 約 $800 \mathrm{~m}$ に位置し, ウィバル周辺では唯一大規模な水田地帯となっているハインダン（南帆 安, Fig. 1 参照) でコウノトリの探索を行ったところ，18 時頃に水田内に 1 羽を発見した。こ の個体は 18 時 27 分に観察者から見えない木陰に入ってしまい, それ以降あたりが暗くなって あここから飛び出すことがなく, 単独でこの場所にねぐらをとったものと考えられた。この日 タルマイに稀ぐらをとったコウノトリは10 羽だったので (Ezaki \& Miyara in press, Appendix 1 参照), 就時個体数をみる限り, この時期にも島内には 11 羽のコウノトリがいたことになる。

このように断片的な情報ながら, 1993 年 11 月に 11 羽の群で与那国島に姿を現したコウノト リが翌年 3 月までそのまま島内に滞在していた可能性は高いと思われる。3 月 19 日に爆竹の音 に驚いて群がタルマイを飛び去った後は，1 羽もしくは 2 羽が島内各所で散見されたにとどま り, 大部分の個体はこの時点で島を飛び去ったと推测される (Appendix 1参照)。この後, 4 月 中はウィバルで 2 羽の姿が何度か認められたが，7月にはくちばしの傷ついた 1 羽のみが認め られるようになり，この個体む与那国島を直撃した台風 13 号の通過後 8 月 9 日にウィバル近 くの牧草地で死体として発見され，これ以降島内のコウノトリの目撃記録は完全にとだえた (松田 私信)。

\section{謝辞}

杉本和章氏, 松田晃源氏, 与那覇仁一氏をはじめとする与那国町教育委員会の方々には調査 期間を通じて大変お世話になった。崎山陽一郎氏, 山田元一郎氏と佐竹潔氏にはコウノトリの 情報收集の面で, 藤巻裕蔵教授と米田重玄氏には文献収集の面で大いにお世話になった。また, 遠藤知二博士には原稿を読んでいただき貴重な助言をいただいた。これらの方々に厚くお礼を 申し上げる。また, 兵庫県教育委員会からは江崎の現地調査の資金援助をうけた。ここに謝意 を表したい。 


\section{引用文献}

Blakiston, T. \& Pryer, H. 1878. A catalogue of the birds of Japan. Ibis 7: 207-250.

Ezaki, Y. \& Miyara, Z. in press. Communal roosting of wintering Oriental White Storks Ciconia boyciana in Yonaguni Island, the westernmost Japan. Jap. J. Ornithol.

藤巻裕蔵 1988. 北海道におけるコウノトリの記録. 日鳥学誌 37: 37-38.

樋口行雄 1976. 三重県で発見されたコウノトリについて. 山階鳥研報 8: 213-215.

池田 啓 1994. コウノトリの飼育下繁殖と野生復㷌. 関西自然保護機構会報 16: 123-130.

清棲幸保 1952. 日本鳥類大図鑑. 東京, 講談社.

丹羽甲子郎 1892. 鳥日記. 動物学雑誌 4: 271-273.

小笠原 暠・泉 祐一 1977. 東北地方に渡来したコウノトリ。山階鳥研報 9: 121-127.

日本鳥学会 1974. 日本鳥類目録. 東京, 学研.

但馬文化協会 1984. コウノトリ物語. 豊岡, 船田企画.

Appendix 1. Records of Oriental White Storks gained in Yonaguni Island between November 1993 and March 1994. Flock size of storks at each scan of each site is given with approximate time of a day the record was taken (EM: -0800 ; M: 0801-1200; A: 1201-1800; LA: 1801-) in parentheses. Columns filled with symbols (-) indicate that the site was not searched for storks on the day. Flock sizes at Tarumai on and before 24 February are the minimum values, since the vision from the observation point did not cover the whole area of the valley at the time.

\begin{tabular}{|c|c|c|c|c|c|}
\hline \multirow{2}{*}{ Date } & \multicolumn{5}{|c|}{ Flock size of storks recorded at } \\
\hline & Mantabaru & Tarumai & Ubungita & Wibaru & Other sites \\
\hline $11 / 24 / 93$ & $11(\mathrm{M}), 11(\mathrm{~A})$ & - & - & - & \\
\hline $11 / 25 / 93$ & $11(\mathrm{~A})$ & - & - & - & \\
\hline $11 / 26 / 93$ & $11(\mathrm{~A})$ & - & - & - & $11^{* \#}(\mathrm{~A})$ \\
\hline $11 / 27 / 93$ & $0(\mathrm{~A})$ & $11(\mathrm{~A})$ & - & - & \\
\hline $11 / 28 / 93$ & $0(\mathrm{~A})$ & $9 *(\mathrm{~A})$ & - & - & \\
\hline $12 / 03 / 93$ & - & $11^{\#}(\mathrm{EM})$ & - & - & \\
\hline $12 / 05 / 93$ & $0(\mathbf{L A})$ & $9(\mathrm{LA})$ & - & - & \\
\hline $12 / 06 / 93$ & $0(\mathbf{M})$ & $9(\mathrm{M})$ & - & - & \\
\hline $12 / 23 / 93$ & - & - & - & $1^{* \#}(\mathrm{~A})$ & \\
\hline $12 / 24 / 93$ & $0(\mathrm{~A})$ & $5(M)$ & - & $0(\mathbf{M})$ & \\
\hline $01 / 03 / 94$ & $O(\mathbf{A})$ & $8(\mathrm{~A})$ & - & $0(\mathrm{~A})$ & \\
\hline $01 / 04 / 94$ & $0(\mathrm{M}), 0(\mathrm{LA})$ & $2(\mathrm{M}), 3(\mathrm{LA})$ & - & $0(\mathrm{M})$ & \\
\hline $01 / 08 / 94$ & $0(\mathrm{M}), 0(\mathrm{~A})$ & $3(\mathrm{M}), 3(\mathrm{~A})$ & - & $\mathrm{O}(\mathrm{M})$ & \\
\hline $01 / 09 / 94$ & & - & - & $1(\mathrm{~A})$ & \\
\hline $01 / 10 / 94$ & $0(\mathrm{~A})$ & $2(\mathrm{~A})$ & - & $0(\mathrm{~A})$ & \\
\hline $01 / 11 / 94$ & $0(\mathbf{M})$ & $2(\mathrm{M})$ & - & $0(M)$ & \\
\hline $01 / 15 / 94$ & $0(\mathrm{~A})$ & $6(\mathrm{~A})$ & - & $0(\mathrm{~A})$ & \\
\hline $01 / 21 / 94$ & $0(A)$ & $9(\mathrm{~A})$ & - & $0(\mathrm{~A})$ & \\
\hline $01 / 23 / 94$ & $0(\mathrm{EM})$ & $10(\mathrm{EM})$ & - & $1(\mathrm{M})$ & \\
\hline $01 / 28 / 94$ & $0(\mathrm{LA})$ & $5(\mathrm{LA})$ & - & - & \\
\hline $01 / 29 / 94$ & - & - & - & $1(\mathrm{~A})$ & \\
\hline $01 / 30 / 94$ & $0(\mathrm{~A})$ & $4(\mathrm{~A})$ & - & $0(\mathrm{~A})$ & \\
\hline $02 / 02 / 94$ & $0(\mathrm{~A})$ & $5^{*}(\mathrm{~A})$ & - & $0(\mathrm{~A})$ & \\
\hline $02 / 06 / 94$ & - & $10^{\#(\mathrm{EM})}$ & - & - & \\
\hline $02 / 08 / 94$ & - & - & - & - & $2^{\#}(\mathrm{~A})$ \\
\hline
\end{tabular}


Appendix 1. (Continued)

\begin{tabular}{|c|c|c|c|c|c|}
\hline \multirow{2}{*}{ Date } & \multicolumn{5}{|c|}{ Flock size of storks recorded at } \\
\hline & Mantabaru & Tarumai & Ubungita & Wibaru & Other sites \\
\hline $02 / 09 / 94$ & $0(\mathbf{M})$ & $3(\mathrm{M})$ & - & $0(\mathrm{M})$ & $2(\mathrm{M})$ \\
\hline $02 / 18 / 94$ & $0(\mathbf{L A})$ & $8(\mathrm{LA})$ & - & $0(\mathbf{L A})$ & \\
\hline $02 / 20 / 94$ & $0(\mathrm{~A})$ & $4(\mathrm{~A})$ & - & $0(\mathrm{~A})$ & \\
\hline $02 / 21 / 94$ & $2^{*}(\mathrm{~A})$ & $5^{*}(\mathrm{~A})$ & - & $0(\mathrm{~A})$ & \\
\hline $02 / 22 / 94$ & $0(\mathbf{M})$ & $2(\mathrm{M})$ & - & $0(\mathrm{M})$ & \\
\hline $02 / 23 / 94$ & $0(\mathbf{M})$ & $10(\mathrm{M})$ & - & $0(\mathrm{M})$ & \\
\hline $02 / 24 / 94$ & $0(\mathrm{~A})$ & $7(\mathrm{~A})$ & - & $1^{* \#}(\mathrm{~A})$ & \\
\hline $02 / 25 / 94$ & $0(\mathrm{EM}), 0(\mathrm{LA})$ & 9(EM), 9(LA) & - & $2(\mathrm{M})$ & \\
\hline $02 / 26 / 94$ & $0(\mathrm{EM}), 0(\mathrm{LA})$ & $9(\mathrm{EM}), 10(\mathrm{LA})$ & - & $2(\mathrm{M})$ & $1^{* \#}(\mathrm{M})$ \\
\hline $02 / 27 / 94$ & $0(\mathrm{EM}), 0(\mathrm{LA})$ & 10(EM), 10(LA) & - & $1(\mathrm{M})$ & \\
\hline $02 / 28 / 94$ & $0(\mathrm{EM}), 0(\mathrm{LA})$ & 10(EM), 10(LA) & - & - & $1(\mathrm{LA})$ \\
\hline $03 / 01 / 94$ & $0(\mathrm{EM}), 0(\mathrm{LA})$ & 10(EM), 10(LA) & - & $1(\mathrm{EM}), 0(\mathrm{M})$ & $2(\mathrm{M})$ \\
\hline $03 / 02 / 94$ & $0(\mathrm{EM}), 0(\mathrm{LA})$ & $10(\mathrm{EM}), 10^{\mathrm{a}}(\mathrm{LA})$ & - & $0(\mathrm{M})$ & $1(\mathrm{EM})$ \\
\hline $03 / 03 / 94$ & $0(\mathrm{EM}), 0(\mathrm{M}), 0(\mathrm{LA})$ & $0(\mathrm{EM}), 7(\mathrm{~A}), 0(\mathrm{LA})$ & - & - & \\
\hline 03/04/94 & $0(\mathrm{EM}), 0(\mathrm{M})$ & $0(\mathrm{EM}), 9^{*}(\mathrm{M})$ & $9(\mathrm{EM})$ & $1(\mathrm{LA})$ & $2(\mathrm{EM})$ \\
\hline $03 / 05 / 94$ & $0(\mathbf{M})$ & $7(\mathrm{M})$ & - & - & $1(\mathrm{M})$ \\
\hline $03 / 06 / 94$ & $0(\mathrm{LA})$ & $9^{a}(\mathrm{LA})$ & $9(\mathrm{LA})$ & - & \\
\hline 03/07/94 & - & - & $9(\mathrm{EM})$ & $0(\mathrm{M})$ & \\
\hline $03 / 08 / 94$ & $0(\mathrm{EM})$ & $0(\mathrm{EM}), 10^{\#}(\mathrm{~A})$ & $9(\mathrm{EM})$ & $0(\mathrm{M})$ & \\
\hline $03 / 09 / 94$ & $0(\mathrm{LA})$ & $0(\mathbf{L A})$ & $8(\mathrm{LA})$ & - & \\
\hline $03 / 10 / 94$ & $0(\mathrm{LA})$ & $0(\mathbf{L A})$ & $2(\mathrm{LA})$ & - & \\
\hline $03 / 11 / 94$ & $0(\mathbf{E M})$ & $O(\mathrm{EM})$ & $9(\mathrm{EM})$ & $0(\mathbf{M})$ & \\
\hline $03 / 12 / 94$ & $0(\mathrm{EM})$ & $0(\mathrm{EM})$ & $9(\mathrm{EM})$ & - & \\
\hline $03 / 13 / 94$ & $0(\mathrm{LA})$ & $0(\mathrm{LA})$ & $0(\mathrm{LA})$ & - & \\
\hline $03 / 14 / 94$ & $0(\mathrm{LA})$ & $0(\mathrm{~A})$ & $9(\mathrm{EM})$ & $1(\mathrm{EM})$ & \\
\hline $03 / 15 / 94$ & $0(\mathbf{M})$ & $0(\mathbf{M})$ & $10(\mathrm{EM})$ & $1(\mathrm{M})$ & \\
\hline $03 / 16 / 94$ & $0(\mathrm{EM})$ & $10(\mathrm{EM})$ & $0(\mathrm{EM})$ & - & \\
\hline $03 / 17 / 94$ & $0(\mathrm{EM}), 0(\mathrm{~A})$ & $10(\mathrm{EM}), 0(\mathrm{~A})$ & $0(\mathrm{~A})$ & $0(\mathrm{EM})$ & \\
\hline $03 / 18 / 94$ & $0(\mathrm{LA})$ & $8(\mathrm{~A})$ & $0(\mathrm{EM})$ & - & \\
\hline $03 / 19 / 94$ & $0(\mathrm{EM})$ & $10(\mathrm{EM})^{\mathrm{a}}$ & $0(\mathrm{EM})$ & - & \\
\hline $03 / 21 / 94$ & $0(\mathrm{LA})$ & $0(\mathrm{LA})$ & - & $2(\mathrm{LA})$ & \\
\hline $03 / 22 / 94$ & $0(\mathrm{EM})$ & $0(\mathrm{EM})$ & $1(\mathrm{EM})$ & $0(\mathrm{EM})$ & \\
\hline $03 / 23 / 94$ & $0(\mathrm{EM})$ & $0(\mathrm{EM})$ & $1(\mathrm{EM})$ & $1(\mathrm{EM})$ & \\
\hline $03 / 24 / 94$ & $0(\mathrm{EM})$ & $0(\mathrm{EM})$ & - & - & \\
\hline $03 / 25 / 94$ & $0(\mathrm{EM})$ & $0(\mathrm{EM})$ & $1(\mathrm{EM})$ & $1(\mathrm{EM})$ & \\
\hline $03 / 27 / 94$ & $0(\mathrm{EM})$ & $0(\mathrm{EM})$ & $0(\mathrm{EM})$ & $0(\mathrm{EM})$ & \\
\hline $03 / 28 / 94$ & - & - & - & - & $1^{*}(\mathrm{~A})$ \\
\hline
\end{tabular}

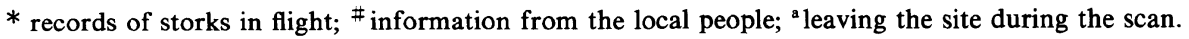

